\section{The Outlaw Ocean: Journeys Across the Last Untamed Frontier}

\author{
By lan Urbina, 2019, Alfred A. Knopf, New York, USA, 546 pages, \\ ISBN: 978-0-451-49294-4, \$30.00 USD
}

Reviewed by D. James Baker

Because most of the ocean is beyond the reach of authorities and law enforcement, we don't hear much about the clandestine side of the marine world. And up to now, most observers have assumed that illegal activities are a small percentage, maybe $10 \%$ of the total marine economy. But new techniques of observation, helped by more accurate satellite observations and computer-aided data analysis, together with more at-sea marine security, show that the ocean's dark economy could be much bigger than that. For example, Daniel Pauly and his group at the University of British Columbia (Pauly and Zeller, 2016) demonstrate that as much as $40 \%$ of total global fishery catch goes unreported.

To help expose this hidden world, Ian Urbina took four years off from his day job at the New York Times to go to sea in as many parts of the ocean as he could to document illegal activities. The Outlaw Ocean: Journeys Across the Last Untamed Frontier, published by Knopf, is an impressive but disturbing picture of how existing laws and regulations are failing to halt destructive actions. From illegal fishing in protected waters to piracy and shipbreaking, the Pulitzer Prizewinning author brings us stark images of a world of shady characters, impossible working conditions, and governments that look the other way. One of the most interesting parts of the book is the 84 pages of notes, telling how he made his contacts, put the plans together, and the myriad helpers he had. He provides a comprehensive bibliography of news articles, journals, and books.

Oceanographers will resonate with Urbina's education as a seagoing observer, and the problems and joys of being at sea. The book is long (546 pages), but it reads like an adventure story, recounting for example how the author got caught up in the fishing life of Cambodians treated like slaves or the chasing of illegal fishing boats off Palau. In 15 fast-moving chapters, his story starts with a battle to stop illegal whaling in stormy Antarctic waters, conflicts over new oil drilling off Brazil, and the sorry state of many fishing vessels. Urbina shows how fish are caught in restricted areas and reveals the workings of maritime repo men. With a special focus on people at sea, he includes life on an abandoned oil rig, piracy off Somalia, the ocean mercenaries who repossess ships for creditors, and doctors at sea providing abortions illegal on shore. $\mathrm{He}$ has an important chapter on the "magic pipes" that allow cruise ships to empty their old oil and other waste directly into the ocean.

As I read about his adventures in Somalia, I was reminded of the abortive first phases of the 1977 INDEX (Indian Ocean Experiment) that Henry Stommel and Roberto Frasetto organized to monitor the boundary currents off Somalia (Frasetto, 1992). After much bribery and failed attempts, they finally got bottom instruments in place. But when they came back and couldn't find them, they were mysteriously advised to look in the desert. The instruments had been recovered and put on shore by local villagers who saw them as malevolent influences on the local fisheries.

Urbina exposes corrupt administrations and emphasizes the inability of developing countries to effectively monitor, control, and enforce marine policies in general. His examples are further evidence that existing laws and regulations, although well intentioned and internationally supported, are not up to the cur-

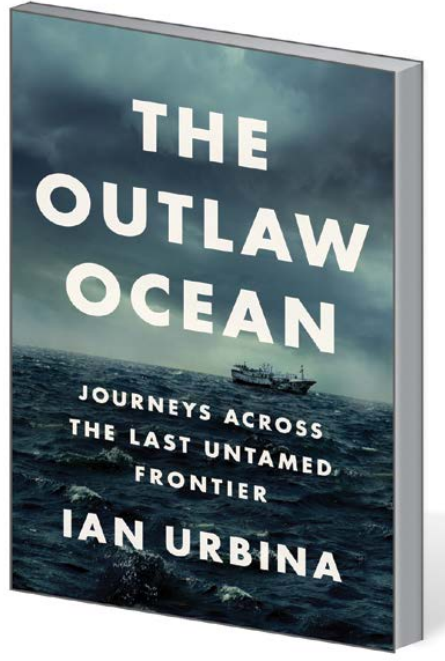

rent challenge. As he shows in compelling and sometimes grisly detail, compliance is low, and penalties are easy to evade.

The book concludes with a chapter, "Reining in the Outlaw Ocean," that focuses on support for existing organizations. That's all well and good. But these organizations are hampered by weak regulations. In many regions, current laws support overfishing, don't protect coral reefs, and permit resource extraction in fishery nursery grounds. The fact is that we need new rules with real legal teeth and stronger governmental action. Until marine policymakers have better knowledge on a gut level about these illegal activities, it is likely that the situation will continue. Urbina's book should be required reading for all marine policymakers.

\section{REFERENCES}

Pauly, D., and D. Zeller. 2016. Catch reconstructions reveal that global marine fisheries catches are higher than reported and declining. Nature Communications 7:10244, https://doi.org/10.1038/ ncomms10244.

Frasetto, R. 1992. The INDEX Experiment. Oceanus magazine, Special Issue on Henry Stommel.

\section{AUTHOR}

D. James Baker (djamesbaker@comcast.net) was the Administrator of the National Oceanic and Atmospheric Administration and Undersecretary of Commerce for Oceans and Atmosphere from 1993 to 2001, and the co-founder and first president of The Oceanography Society. 